\title{
Thermal Analysis of TRIO-CINEMA Mission
}

\section{Jaegun Yoo ${ }^{1}$, Ho Jin ${ }^{1 \dagger}$, Jongho Seon ${ }^{1}$, Yun-Hwang Jeong ${ }^{2}$, David Glaser ${ }^{3}$, Dong-Hun Lee ${ }^{1}$, and Robert P. Lin ${ }^{1,3}$}

\author{
${ }^{1}$ School of Space Research, Kyung Hee University, Yongin 446-701, Korea \\ ${ }^{2}$ Satrec Initiative, Daejeon 305-811, Korea \\ ${ }^{3}$ Space Science Laboratory, University of California, Berkeley CA 94705, USA
}

Thermal analysis and control design are prerequisite essential to design the satellite. In the space environment, it makes satellite survive from extreme hot and cold conditions. In recent years CubeSat mission is developed for many kinds of purpose. Triplet Ionospheric Observatory (TRIO)-CubeSat for Ion, Neutral, Electron, MAgnetic fields (CINEMA) is required to weigh less than $3 \mathrm{~kg}$ and operate on minimal $3 \mathrm{~W}$ power. In this paper we describe the thermal analysis and control design for TRIO-CINEMA mission. For this thermal analysis, we made a thermal model of the CubeSat with finite element method and NX6.0 TMG software is used to simulate this analysis model. Based on this result, passive thermal control method has been applied to thermal design of CINEMA. In order to get the better conduction between solar panel and chassis, we choose aluminum 6061-T6 for the material property of standoff. We can increase the average temperature of top and bottom solar panels from $-70^{\circ} \mathrm{C}$ to $-40^{\circ} \mathrm{C}$ and decrease the average temperature of the magnetometer from $+93^{\circ} \mathrm{C}$ to $-4^{\circ} \mathrm{C}$ using black paint on the surface of the chassis, inside of top \& bottom solar panels, and magnetometer.

Keywords: thermal analysis, thermal control design, CubeSat, picosatellite

\section{INTRODUCTION}

Triplet Ionospheric Observatory (TRIO)-CubeSat for Ion, Neutral, Electron, MAgnetic fields (CINEMA) is a space science mission with three identical CubeSats. Three institutes are collaborating to develop three CINEMA CubeSats: i) two CubeSats by Kyung Hee University (KHU) under its World Class University (WCU) program, ii) one CubeSat by UC Berkeley under the National Science Foundation (NSF) support, and iii) three magnetometers by Imperial College, respectively. CINEMA is a 3-unit CubeSat, with an approximate size of $10 \mathrm{~cm} \times 10$ $\mathrm{cm} \times 30 \mathrm{~cm}$ and mass less than $3 \mathrm{~kg}$. Attitude control system uses two torque coils, one sun sensor and one magnetometer and spins CINEMA spacecraft at $4 \mathrm{rpm}$ with the spin axis perpendicular to the ecliptic plane as shown in Fig. 1. Three identical CubeSats will be built to carry out following scientific objectives: i) stereo imaging of magnetospheric energetic neutral atom, ii) multi-point mea-

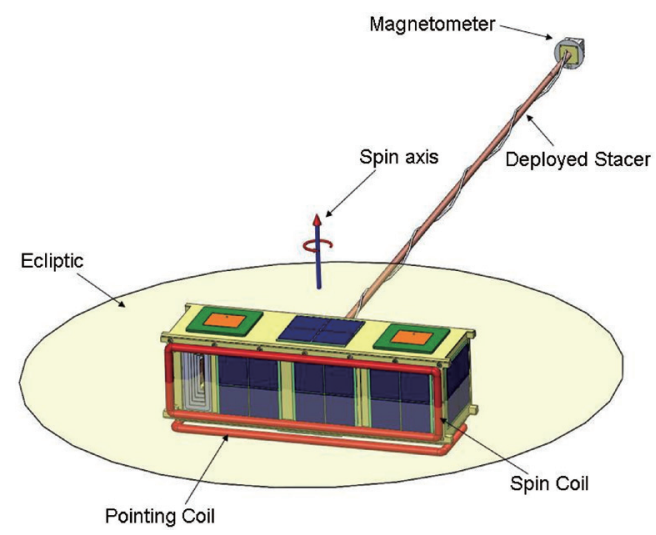

Fig. 1. Attitude of CINEMA in orbit. CINEMA: CubeSat for Ion, Neutral, Electron, MAgnetic fields. (c) This is an Open Access article distributed under the terms of the Creative Commons Attribution Non-Commercial License (http://creativecommons.org/licenses/by-nc/3.0/) which permits unrestricted non-commercial use, distribution, and reproduction in any medium, provided the original work is properly cited.
Received Dec 20, 2011 Revised Jan 16, 2012 Accepted Feb 24, 2012 ${ }^{\dagger}$ Corresponding Author

E-mail: benho@khu.ac.kr

Tel: +82-31-201-3865 Fax: +82-31-206-2470 


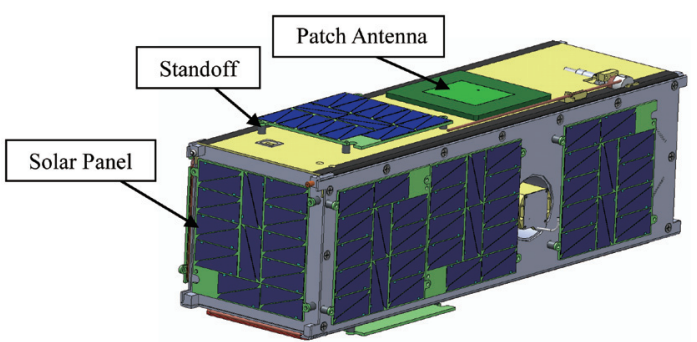

Fig. 2. External configuration of CINEMA. CINEMA: CubeSat for lon, Neutral, Electron, MAgnetic fields.

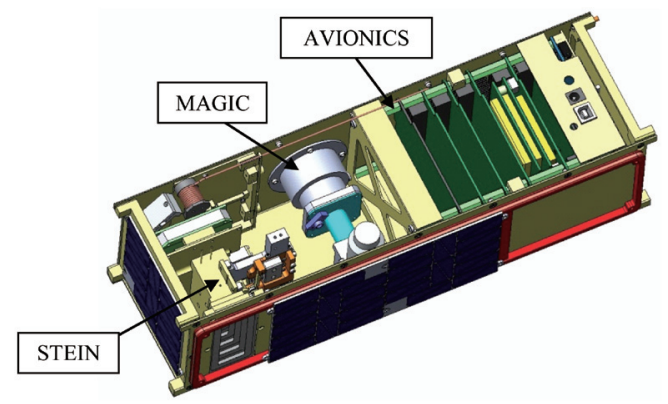

Fig. 3. Internal configuration of CINEMA. CINEMA: CubeSat for lon, Neutral, Electron, MAgnetic fields.

surements of suprathermal electrons and ions associated with auroral acceleration as well as electron microbursts, and iii) complementary measurements of magnetic fields for particle data. Each satellite is equipped with a SupraThermal Electron, Ion, Neutral (STEIN) instrument covering the energy range $\sim 2-200 \mathrm{keV}$, and a 3-axis magnetometer of magnetoresistive sensors. CINEMA will be launched in July of 2012 and mission duration is one year. Operational orbit is $800 \mathrm{~km}$ sun-synchronous. Main components of external CINEMA consist of a magnetometer, solar panels, standoff, and patch antennas as seen in Fig. 2. In our case external surface of the satellite is covered with a lot of solar panels which are exposed to the sun except top \& bottom side panels. The thermal conditions of external CINEMA was that the magnetometer is isolated from the body and top \& bottom solar panels cannot receive light from the sun in the orbit. Main components of internal CINEMA consist of avionics, the MAGnetometer Imperial College (MAGIC), and the STEIN as seen in Fig. 3. The thermal conditions of internal CINEMA is how to maintain operating temperature range of each component.

\section{THERMAL ANALYSIS}

\subsection{Requirements and Conditions for Thermal Analysis}

The objective of thermal analysis is to maintain all subsystems and components of a spacecraft within their operating temperature limits for all mission phases (Gilmore 2002, Wertz \& Larson 2008). Space environment can make all subsystems get variant temperature. So we have to maintain all subsystems and components within their operating temperature limits. There is some difference between operating temperature limit and non-operating temperature limit. Table 1 shows operating temperature limits of CINEMA component. Thermal control design and analysis were based on this operating temperature limit of each component. When the temperature of the battery is decreased less than $-10^{\circ} \mathrm{C}$, lifetime of the battery will be shortened rapidly. On the contrary to this, when the temperature of detector is increased, thermal noise will be occurred on the detector. So it is very important to maintain the operating temperature limits of individual components in the orbit. Table 2 is orbit condition used in thermal analysis for CINEMA. For this thermal analysis, we assumed that the solar flux is $1,378 \mathrm{~W} / \mathrm{m}^{2}$ at the spring or autumn equinoxes and used the fixed value of infrared radiation (IR) flux and albedo.

Table 1. Operating temperature ranges of CINEMA components.

\begin{tabular}{lc}
\hline \multicolumn{1}{c}{ Component } & Operating Temp limit $\left({ }^{\circ} \mathrm{C}\right)$ \\
\hline Emhiser TX & -40 to +85 \\
OBC (mother board) & -40 to +85 \\
SD card & -40 to +85 \\
RTC coin battery & -30 to +80 \\
OBC (processor board) & -40 to +85 \\
EPS & -40 to +85 \\
Battery & -10 to +50 \\
Helium receiver & -30 to +70 \\
Magnetometer & -120 to +50 \\
Sunsensor & -40 to +125 \\
Solar cell & -100 to +100 \\
Structure & -45 to +65
\end{tabular}

CINEMA: CubeSat for lon, Neutral, Electron, MAgnetic fields, TX: Transmitter, OBC: OnBoard Computer, SD: Secure Digital, RTC: Real Time Clock.

Table 2. Orbit condition of CINEMA.

\begin{tabular}{lc}
\hline \multicolumn{1}{c}{ Parameter } & Value \\
\hline Planet & Earth \\
Orbit type & Sun-synchronous \\
Altitude $(\mathrm{km})$ & 800 \\
Eccentricity & 0 \\
Orbit inclination $(\mathrm{deg})$ & 98.57 \\
Solar declination $(\mathrm{deg})$ & 0 \\
Solar flux $\left(\mathrm{W} / \mathrm{m}^{2}\right)$ & 1,378 \\
IR flux $\left(\mathrm{W} / \mathrm{m}^{2}\right)$ & 237 \\
Albedo vs Latitude & 0.306 \\
Number of intervals per orbit & 10 \\
Number of calculations per spin & 6 \\
Local time at ascending node & $10: 30: 00$ \\
\hline
\end{tabular}

CINEMA: CubeSat for Ion, Neutral, Electron, MAgnetic fields, IR: infrared radiation. 
The heat dissipation of CINEMA has different value in each operating mode as shown in Table 3. Therefore, it is necessary to analysis when the heat dissipation of CINEMA is the highest value and the lowest value. We have analyzed two different cases at the Science mode and Safe mode. Fig. 4a shows the CAD model of avionics stack and Fig. $4 \mathrm{~b}$ shows the thermal analysis model of avionics stack. Average heat dissipation was used for board level thermal analysis of avionics stack. At the safe mode, the heat dissipation of avionics is occurred only from stack number 1 through stack number 4 .

\subsection{Process for Thermal Analysis Using NX6.0 TMG}

Computer application program, NX6.0 TMG (Siemens, Munich, Germany) is used to construct the thermal

Table 3. Average heat dissipation of avionics stack in one orbit.

\begin{tabular}{|c|c|c|c|c|}
\hline \multirow{2}{*}{\multicolumn{2}{|c|}{ Component }} & \multicolumn{3}{|c|}{ Operating mode in one orbit ( $\mathrm{mW})$} \\
\hline & & Safe mode & ACS mode & Science mode \\
\hline & EmhiserTX & 0 & 0 & 270 \\
\hline \multirow{11}{*}{$\begin{array}{l}\text { Avionics } \\
\text { stack }\end{array}$} & 1-OBC & 110 & 110 & 110 \\
\hline & 2-EPS & 100 & 100 & 100 \\
\hline & 3-BATT & 100 & 100 & 100 \\
\hline & $4-\mathrm{RX}$ & 222 & 8 & 8 \\
\hline & 5 -IIB & 0 & 250 & 250 \\
\hline & 6-MAGIC & 0 & 223 & 806 \\
\hline & 7-HVPS & 0 & 0 & 357 \\
\hline & Torque coil & 0 & 800 & 0 \\
\hline & Sunsensor & 252 & 25 & 25 \\
\hline & STEIN & 0 & 0 & 344 \\
\hline & Magnetometer & 0 & 0 & 272 \\
\hline \multicolumn{2}{|c|}{ Total usage } & 557 & 1,615 & 2,642 \\
\hline
\end{tabular}

ACS: attitude control system, TX: transmitter, OBC: onboard computer , EPS: electric power supply, BATT: battery, RX: receiver, IIB: internal interface board, MAGIC: MAGnetometer Imperial College, HVPS: high voltage power supply, STEIN: SupraThermal Electron, Ion, Neutral.

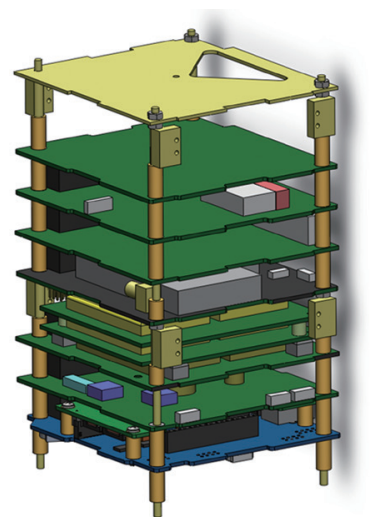

(a)

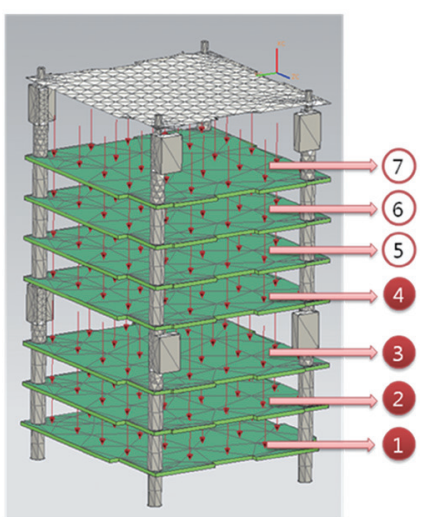

(b)
Fig. 4. (a) CAD model of avionics stack. (b) Thermal analysis model of avionics stack. analysis model for CINEMA. The NX6.0 TMG program is based on the finite elements method (FEM) and it has capabilities of radiation exchange, conduction exchange and environmental heating by direct sunlight, albedo and IR emitted by the Earth. Fig. 5 shows steps of thermal analysis process for CINEMA. Because solving time of thermal analysis simulation is reduced more by using a rectangular shape of mesh than using a triangular shape of mesh, we made a mesh with rectangular shape for all of external components of CINEMA, as shown in Fig. 6. The design of internal components of CINEMA is more complicate than external components. So we made

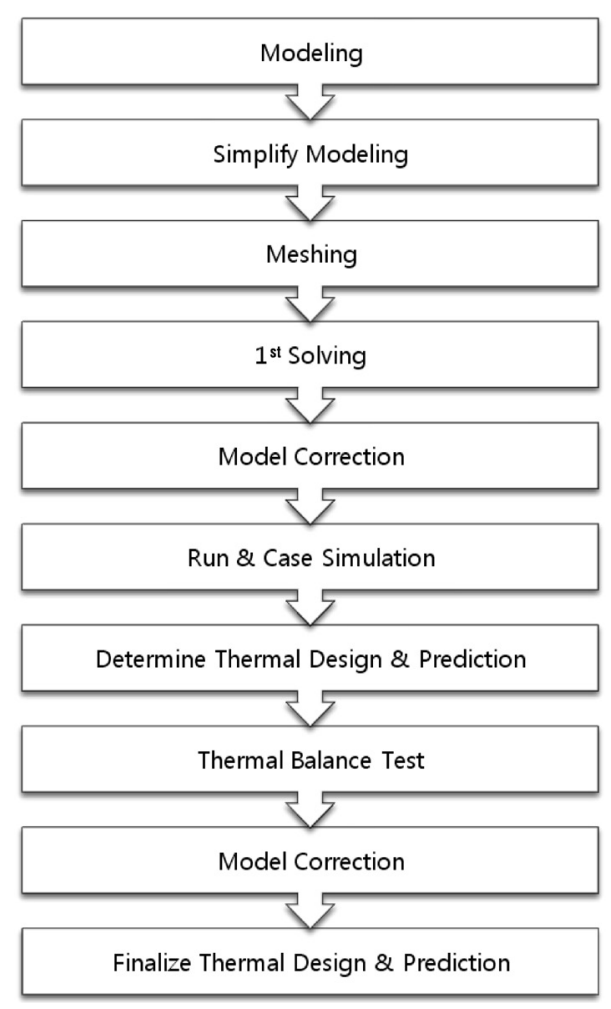

Fig. 5. Process for thermal analysis using NX6.0 TMG.

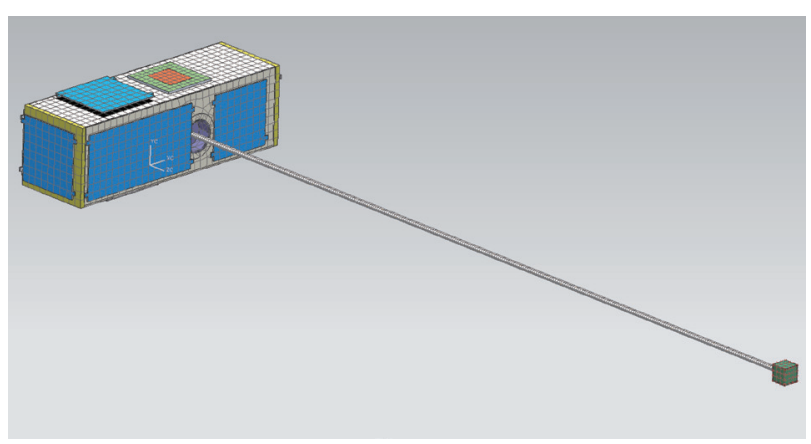

Fig. 6. External configuration of the thermal analysis model for CINEMA. CINEMA: CubeSat for Ion, Neutral, Electron, MAgnetic fields. 
a mesh with rectangular shape and triangular shape for internal components of CINEMA, as shown in Fig. 7. Table 4 is material properties used in thermal analysis for CINMEA that are referenced from www.matweb.com web site. Many components of CINEMA consist of aluminum 6061 or 5052.

In order to get the better conduction between solar panel and chassis, we choose aluminum 6061-T6 for the material of standoff. Table 5 is thermo-optical properties used in thermal analysis for CINEMA that are offered by University of California Berkeley. In the table, $\alpha$ is absorptance or emittance at the solar spectrum, $\varepsilon$ is absorptance or emittance at the room-temperature-body spectrum, and $\alpha / \varepsilon$ is the ratio of absorptance to emittance. Because internal components emit IR, the absorptance of internal component has equivalent value as emittance. In order to calculate easily the transient heat transfer of the CINEMA,

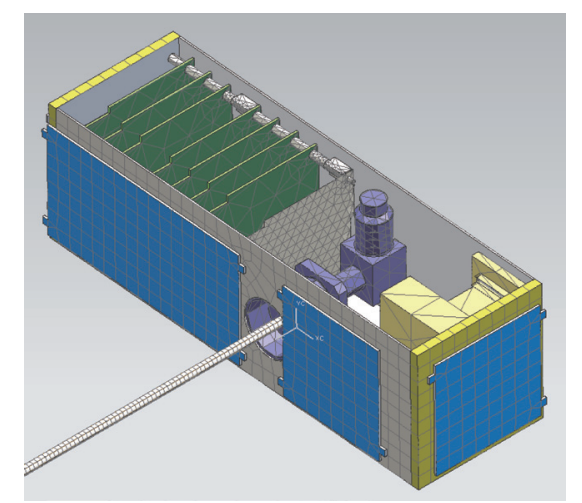

Fig. 7. Internal configuration of the thermal analysis model for CINEMA. CINEMA: CubeSat for lon, Neutral, Electron, MAgnetic fields.
FEM is used for thermal analysis. To develop a thermal network and apply numerical techniques to its solution, we subdivide the thermal system into finite subvolumes called nodes. The thermal properties of each node are considered to be concentrated at the central nodal point of each subvolume. Each node represents two thermalnetwork elements, a temperature (potential) and a thermal mass (capacitance). Conduction conductors for rectangular nodes are computed from the following (Gilmore 2002)

$$
G=\frac{k A}{L}
$$

where $G$ is thermal conductance $\left(\mathrm{W} / \mathrm{m}^{2} /{ }^{\circ} \mathrm{C}\right), k$ is thermal conductivity $\left(\mathrm{W} / \mathrm{m}-{ }^{\circ} \mathrm{C}\right), A$ is cross-sectional area through which heat flows $\left(\mathrm{m}^{2}\right)$, and $L$ is the distance between adjoining nodes $(\mathrm{m})$. The thermal conductivity of materials may vary with temperature or other influencing factors within the system, the cross-sectional area and distance between node centers are determined by the size and shape of the adjoining nodes. In the capacitance calculations, necessity to use temperature-dependent properties depends on the degree to which the conductivity changes over the temperature range expected during the analysis.

Two or more parallel conduction paths between nodes can be summed to create one conductor value by the following equation (Gilmore 2002)

$$
G=G_{1}+G_{2}+\cdots+G_{n}
$$

This equation can be helpful in computing an equivalent conductor between two nodes. This equation is used only in case of same materials and same shaped. Two or more series conduction paths between nodes can be combined

Table 4. Material properties of CINEMA.

\begin{tabular}{llccr}
\hline \multicolumn{1}{c}{ Component } & \multicolumn{1}{c}{ Material } & $\begin{array}{c}\text { Density } \\
\left(\mathbf{k g} / \mathbf{m}^{3}\right)\end{array}$ & $\begin{array}{c}\boldsymbol{k} \\
(\mathbf{W} / \mathbf{m}-\mathbf{K})\end{array}$ & $\begin{array}{c}\text { Heat capacity } \\
(\mathbf{J} / \mathbf{k g}-\mathbf{K})\end{array}$ \\
\hline Chassis (top \& bottom) & Al 5052-H32 & 2,680 & 138 & 880 \\
Chassis (end plate) & Al 6061-T6 & 2,700 & 167 & 896 \\
Solar cell PCB & FR4 & 1,900 & 0.23 & 1,200 \\
Standoff & Al6061-T6 & 2,700 & 167 & 896 \\
Patch ANT (copper) & Copper (C10200) & 8,940 & 391 & 385 \\
Patch ANT (rogers) & RT_duroid_6002 & 2,100 & 0.6 & 930 \\
Avionics frame & Al 6061-T6 & 2,700 & 167 & 896 \\
Avionics PCB & FR4 & 1,900 & 0.23 & 1,200 \\
MAG & Al 6061-T6 & 2,700 & 167 & 896 \\
Magnetometer & Al 6061-T6 & 2,700 & 167 & 896 \\
Stacer boom & Elgiloy & 8,300 & 12.5 & 703 \\
STEIN_housing & Al 6061-T6 & 2,700 & 167 & 896 \\
Mount block & Al 6061-T6 & 2,700 & 167 & 896 \\
STEIN_PCB & FR4 & 1,900 & 0.23 & 1,200 \\
STEIN_detector & Silicon & 2,300 & 124 & 794 \\
Baffles & BeCu alloy (UNS C81800) & 8,620 & 218 & 420 \\
Emhiser TX & Al 6061-T6 & 2,700 & 167 & 896 \\
\hline
\end{tabular}

CINEMA: CubeSat for Ion, Neutral, Electron, MAgnetic fields, PCB: printed circuit board, ANT: antenna, MAG: magnetometer, STEIN: SupraThermal Electron, Ion, Neutral, TX: transmitter. 
Table 5. Thermo-optical properties of CINEMA.

\begin{tabular}{llccc}
\hline \multicolumn{1}{c}{ Component } & \multicolumn{1}{c}{ Optical property } & $\boldsymbol{\alpha}$ & $\boldsymbol{\varepsilon}$ & $\boldsymbol{\alpha} / \boldsymbol{\varepsilon}$ ratio \\
\hline Chassis (top \& bottom) & Alodined_aluminum & 0.20 & 0.04 & 5 \\
& and black paint & 0.95 & 0.89 & 1.07 \\
Chassis (end plate) & Alodined_aluminum & 0.20 & 0.04 & 5 \\
Solar cell & ITO-GaAs & 0.92 & 0.85 & 1.08 \\
Solar cell PCB & FR4 and black paint & 0.80 & 0.80 & 1 \\
& & 0.95 & 0.89 & 1.07 \\
Patch ANT (copper) & Copper & 0.30 & 0.03 & 10 \\
Patch ANT (rogers) & Rogers & 0.60 & 0.80 & 0.75 \\
Avionics Frame & Alodined_aluminum & & 0.04 & - \\
Avionics PCB & FR4 & & 0.6 & - \\
MAG & Alodined_aluminum & 0.20 & 0.04 & 5 \\
Magnetometer & Alodined_aluminum & 0.20 & 0.04 & 5 \\
Stacer boom & Black_paint & 0.95 & 0.89 & 1.07 \\
STEIN_housing & Alodined_aluminum & & 0.04 & - \\
Mount block & Alodined_aluminum & & 0.04 & - \\
STEIN_PCB & FR4 & & 0.6 & - \\
STEIN_detector & Aluminum_vapor_deposited & 0.08 & 0.02 & 4 \\
Baffles & Ebanol_C & 0.9 & 0.11 & 8.18 \\
Emhiser TX & Alodined_aluminum & & 0.04 & - \\
\hline
\end{tabular}

CINEMA: CubeSat for Ion, Neutral, Electron, MAgnetic fields, PCB: printed circuit board, ANT: antenna, MAG: magnetometer, STEIN: SupraThermal Electron, Ion, Neutral, TX: transmitter, ITO: indium tin oxide.

to create one conductor value by the following equations (Gilmore 2002)

$$
G_{T}=\frac{1}{\frac{1}{G_{1}}+\frac{1}{G_{2}}+\cdots+\frac{1}{G_{n}}}
$$

This equation is helpful in computing the conductors between two dissimilarly shaped nodes or two nodes of dissimilar materials.

In order to solve conduction among components of CINEMA, it is necessary to calculate the total conductance value. From the Eqs. (1-3), we can obtain the total conductance value between end plate and side plate. It can be calculated as Eqs. (4-6), where $G_{1}$ is conductance value of end plate and $G_{2}$ is conductance value of side plate.

Table 6. Total conductance value of all CINEMA components.

\begin{tabular}{lc}
\hline \multicolumn{1}{c}{ Component } & $\begin{array}{c}\text { Total conductance value } \\
\left(\mathbf{W} / \mathrm{m}^{2} /{ }^{\circ} \mathbf{C}\right)\end{array}$ \\
\hline Solar panel and chassis & 0.005 \\
Patch antenna and chassis & 991.74 \\
Baffles and STEIN housing & 984 \\
Detector and STEIN housing & 993 \\
PCB and STEIN housing & 222 \\
PCB and mount block & 221 \\
STEIN housing and chassis & 960 \\
MAG and chassis & 978.9 \\
Magnetometer and stacer boom & 0.0063
\end{tabular}

CINEMA: CubeSat for Ion, Neutral, Electron, MAgnetic fields, STEIN: SupraThermal Electron, Ion, Neutral, PCB: printed circuit board, MAG: magnetometer.

$$
\begin{aligned}
& G_{1}=167 \mathrm{~W} / \mathrm{m} /{ }^{\circ} \mathrm{C} \times \frac{6.35 \times 10^{-3} \mathrm{~m}^{2}}{3.18 \times 10^{-3} \mathrm{~m}^{2}}=333.5 \mathrm{~W} / \mathrm{m} /{ }^{\circ} \mathrm{C} \\
& G_{2}=138 \mathrm{~W} / \mathrm{m} /{ }^{\circ} \mathrm{C} \times \frac{1.22 \times 10^{-3} \mathrm{~m}^{2}}{156 \times 10^{-3} \mathrm{~m}^{2}}=1.08 \mathrm{~W} / \mathrm{m} /{ }^{\circ} \mathrm{C} \\
& G_{\text {total }}=\frac{1}{\frac{1}{333.5}+\frac{1}{1.08}}=1.08 \mathrm{~W} / \mathrm{m} /{ }^{\circ} \mathrm{C}
\end{aligned}
$$

In the same way, the total conductance value of all CINEMA components can be calculated as seen in Table 6 .

\subsection{Results of Thermal Analysis}

We could get results of thermal analysis using NX6.0 TMG program at the two different cases, safe mode and science mode. The one orbit period of CINEMA is 5,798 seconds and the end time of simulation is 30,000 seconds. All the data in this simulation was recorded every 300 seconds. Fig. 8 shows the analysis temperature of the chassis in the safe mode. The chassis is made of aluminum 5052-H32 and 6061-T6. The thermo-optical property of the chassis is alodined aluminum which has very high ratio of absorptance to emittance. Fig. 9 shows the analysis temperature of solar panels in the safe mode and science mode. The black square line indicates a temperature of the side solar panel and the white circle line indicates a temperature of the top solar panel. In this figure, we can see that the temperature of the top solar panel is much lower than the side solar panel. It is very dangerous because the 
operating temperature limit of the solar panel is $-100^{\circ} \mathrm{C}$ to $100^{\circ} \mathrm{C}$. So we need to devise new thermal control approach to increase the temperature of the top and bottom solar panel so that the temperature is within their operating temperature limit. Fig. 10 shows the analysis tempera-

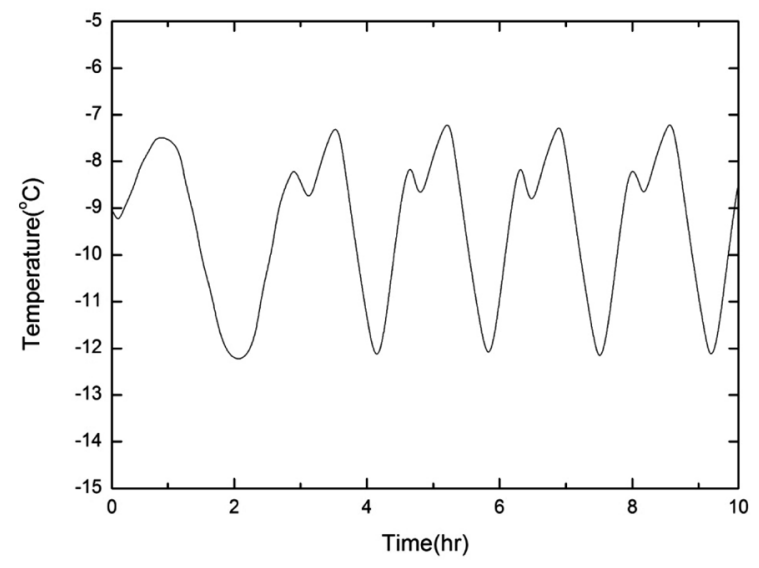

Fig. 8. Temperature of the chassis in the safe mode.

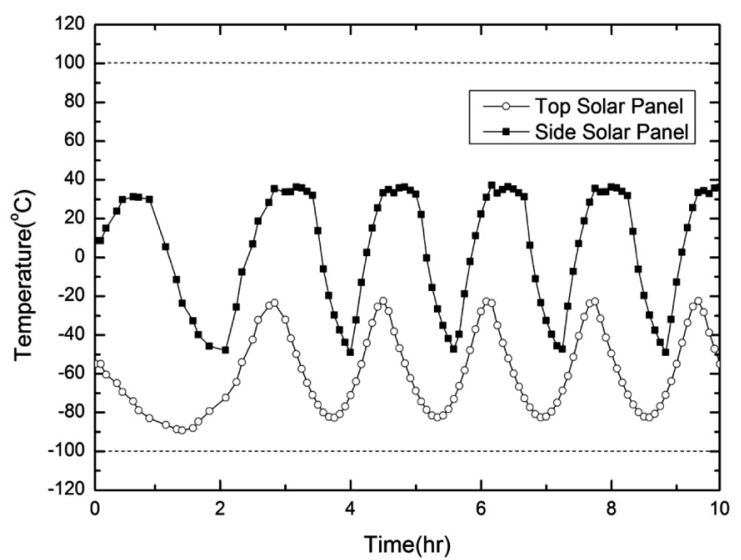

Fig. 9. Temperature of the top and side solar panel in the safe mode.

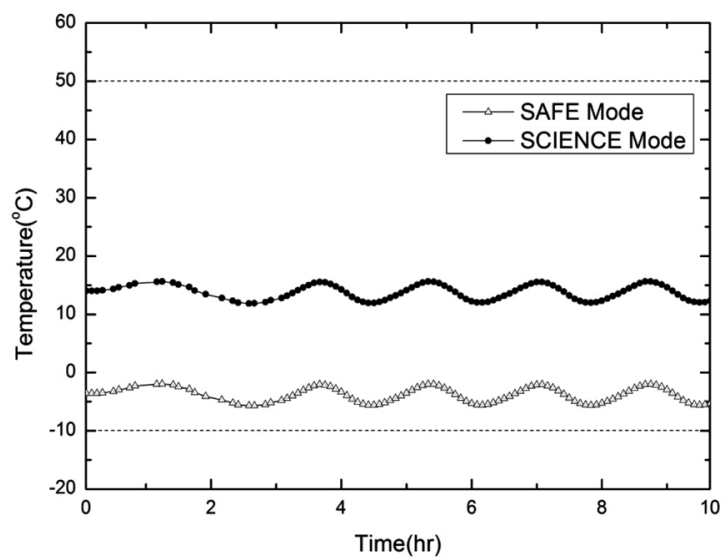

Fig. 10. Temperature of the BATT-PCB in the safe and science mode. PCB: printed circuit board. ture of BATT-printed circuit board (PCB) in the safe mode and science mode. We assumed that the temperature of BATT-PCB has equivalent value with real temperature of battery. So it is not necessary to make the thermal model of battery. The black circle line indicates a temperature in the science mode and the white triangular line indicates a temperature in the safe mode. We can know that the temperature of the battery in safe mode and science mode keep remaining within their operating temperature limit. Fig. 11 shows the analysis temperature of STEIN detector in the safe mode and science mode. The black circle line indicates a temperature in the science mode and the white triangular line indicates a temperature in the safe mode. Because the material property of STEIN detector is silicon which has very high conductivity, the temperature of STEIN detector is depending on a temperature of the STEIN housing which is made of aluminum 6061-T6. Fig. 12 shows the analysis temperature of the magnetometer in the safe mode. We can see that the temperature of magnetometer increased near $100^{\circ} \mathrm{C}$. There is no thermal

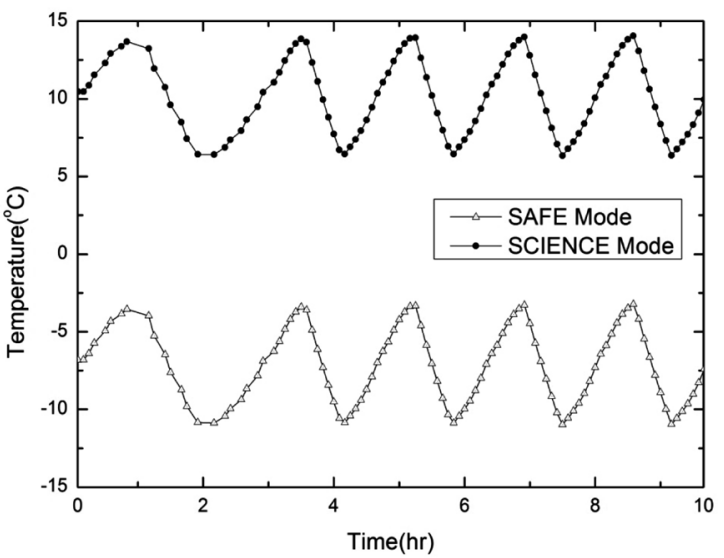

Fig. 11. Temperature of the STEIN detector in the safe and science mode. STEIN: SupraThermal Electron, Ion, Neutral.

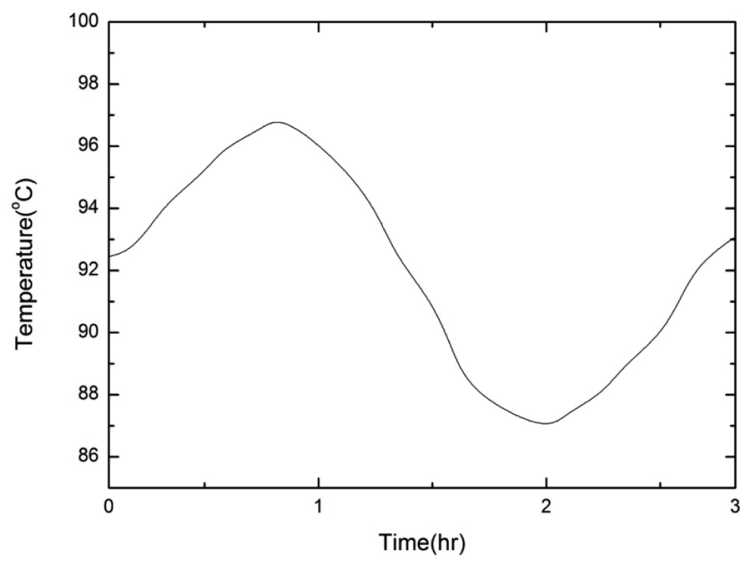

Fig. 12. Temperature of the magnetometer in the safe mode. 
interaction between the body of CINEMA and the magnetometer and the thermo-optical property of the magnetometer is alodined aluminum which has very high ratio of absorptance to emittance. That was because the temperature of magnetometer increased near $100^{\circ} \mathrm{C}$. So we need to devise new thermal control approach to decrease the temperature of the magnetometer so that the temperature is within their operating temperature limit $\left(-120 \sim 50^{\circ} \mathrm{C}\right)$. Tables $7-10$ summarize the analysis results of each component.

Table 7. Temperature of external components.

\begin{tabular}{|c|c|c|c|c|}
\hline \multirow[b]{2}{*}{ Components } & \multicolumn{2}{|c|}{ Safe mode } & \multicolumn{2}{|c|}{ Sscience mode } \\
\hline & $\begin{array}{c}\text { Average } \\
\text { temp }\left({ }^{\circ} \mathrm{C}\right)\end{array}$ & $\begin{array}{l}\text { Min, Max } \\
\text { temp }\left({ }^{\circ} \mathrm{C}\right)\end{array}$ & $\begin{array}{l}\text { Average } \\
\text { temp }\left({ }^{\circ} \mathrm{C}\right)\end{array}$ & $\begin{array}{l}\text { Min, Max } \\
\text { temp }\left({ }^{\circ} \mathrm{C}\right)\end{array}$ \\
\hline Chassis & $-10 \sim-6$ & $-13 \sim-3$ & $5 \sim 10$ & $2 \sim 14$ \\
\hline $\begin{array}{l}\text { Solar panel } \\
\text { (top \& Bottom) }\end{array}$ & $-70 \sim-31$ & $-92 \sim-19$ & $-63 \sim-17$ & $-82 \sim-6$ \\
\hline Solar panel (side) & $-4 \sim 17$ & $-60 \sim 50$ & $0 \sim 17$ & $-60 \sim 50$ \\
\hline
\end{tabular}

Table 8. Temperature of AVIONICS.

\begin{tabular}{lccccc}
\hline \multirow{2}{*}{ Components } & \multicolumn{2}{c}{ Safe mode } & & \multicolumn{2}{c}{ Science mode } \\
\cline { 2 - 3 } \cline { 5 - 6 } & $\begin{array}{c}\text { Average } \\
\text { temp }\left({ }^{\circ} \mathbf{C}\right)\end{array}$ & $\begin{array}{c}\text { Min, Max } \\
\text { temp }\left({ }^{\circ} \mathbf{C}\right)\end{array}$ & & $\begin{array}{c}\text { Average } \\
\text { temp }\left({ }^{\circ} \mathbf{C}\right)\end{array}$ & $\begin{array}{c}\text { Min, Max } \\
\text { temp }\left({ }^{\circ} \mathbf{C}\right)\end{array}$ \\
\hline Avionics frame & -8 & $-12 \sim-4$ & & 10 & $5 \sim 15$ \\
1 - OBC & -4 & $-10 \sim-2$ & & 13 & $7 \sim 15$ \\
2- EPS & -3 & $-5 \sim-1$ & & 15 & $10 \sim 18$ \\
3- BATT & -3 & $-5 \sim-1$ & & 15 & $10 \sim 18$ \\
4- RX & -2 & $-4 \sim 0$ & & 15 & $10 \sim 18$ \\
5- IIB & -6 & $-8 \sim-4$ & & 20 & $20 \sim 24$ \\
6- MAGIC & -7 & $-9 \sim-4$ & & 30 & $26 \sim 31$ \\
7 - HVPS & -7 & $-10 \sim-5$ & & 22 & $21 \sim 28$ \\
Emhiser TX & -7 & $-10 \sim-4$ & & 10 & $7 \sim 13$ \\
\hline
\end{tabular}

OBC: onboard computer, EPS: electric power supply, BATT: battery, RX: receiver, IIB: internal interface board, MAGIC: MAGnetometer Imperial College, HVPS: high voltage power supply, TX: transmitter.

Table 9. Temperature of MAGIC.

\begin{tabular}{lccccc}
\hline \multirow{2}{*}{ Components } & \multicolumn{2}{c}{ Safe mode } & & \multicolumn{2}{c}{ Science mode } \\
\cline { 2 - 3 } \cline { 5 - 6 } & $\begin{array}{c}\text { Average } \\
\text { temp }\left({ }^{\circ} \mathbf{C}\right)\end{array}$ & $\begin{array}{c}\text { Min, Max } \\
\text { temp }\left({ }^{\circ} \mathbf{C}\right)\end{array}$ & & $\begin{array}{c}\text { Average } \\
\text { temp }\left({ }^{\circ} \mathbf{C}\right)\end{array}$ & $\begin{array}{c}\text { Min, Max } \\
\text { temp }\left({ }^{\circ} \mathbf{C}\right)\end{array}$ \\
\hline MAG housing & -7 & $-11 \sim-4$ & & 10 & $6 \sim 13$ \\
Spacer boom & $-17 \sim-1$ & $-88 \sim 27$ & & $-15 \sim 18$ & $-85 \sim 46$ \\
Magnetometer & 93 & $87 \sim 98$ & & 223 & $217 \sim 228$ \\
\hline
\end{tabular}

MAGIC: MAGnetometer Imperial College, MAG: magnetometer.

Table 10. Temperature of STEIN.

\begin{tabular}{lccccc}
\hline \multirow{2}{*}{ Components } & \multicolumn{2}{c}{ Safe mode } & & \multicolumn{2}{c}{ Science mode } \\
\cline { 2 - 3 } \cline { 5 - 6 } & $\begin{array}{c}\text { Average } \\
\text { temp }\left({ }^{\circ} \mathrm{C}\right)\end{array}$ & $\begin{array}{c}\text { Min, Max } \\
\text { temp }\left({ }^{\circ} \mathrm{C}\right)\end{array}$ & $\begin{array}{c}\text { Average } \\
\text { temp }\left({ }^{\circ} \mathrm{C}\right)\end{array}$ & $\begin{array}{c}\text { Min, Max } \\
\text { temp }\left({ }^{\circ} \mathrm{C}\right)\end{array}$ \\
\hline STEIN (housing) & -7 & $-11 \sim-3$ & & 10 & $5 \sim 14$ \\
STEIN (detector) & -7 & $-10 \sim-3$ & & 10 & $6 \sim 14$ \\
STEIN PCB & -10 & $-14 \sim-8$ & & 40 & $33 \sim 44$ \\
\hline
\end{tabular}

STEIN: SupraThermal Electron, lon, Neutral, PCB: printed circuit board.

\section{THERMAL CONTROL DESIGN}

\subsection{Passive Thermal Control Design}

From previous results of thermal analysis, thermal control approaches are necessary to the top \& bottom solar panel and magnetometer. Thermal control design has two different methods, the one is active thermal control method such as heater or cooler and the other is passive thermal control method such as coatings or surface finishes (Gilmore 2002). In our case, active thermal control method cannot apply to CINEMA because of its small surface and low power. So we selected passive thermal control method for our CINEMA.

In the case of the top \& bottom solar panel, the temperature of the top \& bottom solar panel is very low and near $-100^{\circ} \mathrm{C}$. We thought that we could increase the average temperature of the top and bottom solar panels by using black paint on the surface of chassis and the inside of the top \& bottom solar panels as shown in Fig. 13. The black paint which has a good emittance can emit a radiation from the chassis to the top \& bottom solar panels satisfactorily and the black paint which has a good absorptance can absorb a radiation from the chassis to the top \& bottom solar panels satisfactorily. Radiation is only source to increase the temperature of the top \& bottom solar panel because the top \& bottom solar panel is isolated from the body of CINEMA and the surface area of standoff is very small.

In the case of the magnetometer, the temperature of the magnetometer is very high because the thermo-optical property of the magnetometer is alodine aluminum which has very high ratio of absorptance to emittance. The temperature of the magnetometer is depends on

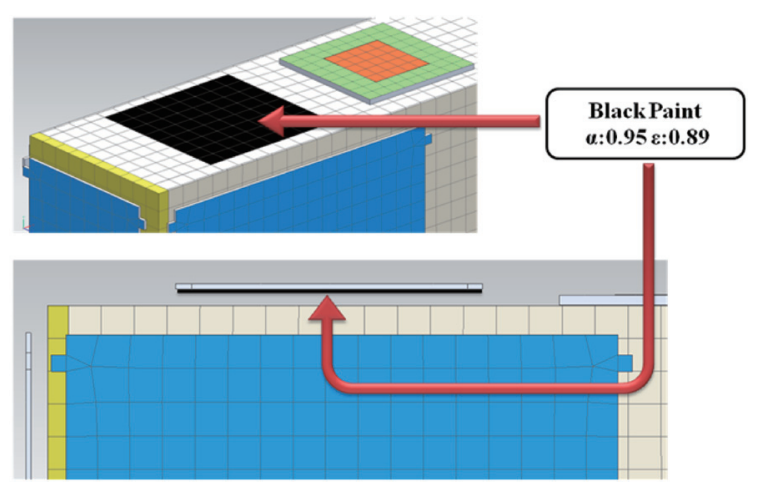

Fig. 13. Black paint as the surface of the chassis and top \& bottom solar panel. 
the ratio of absorptance to emittance. When we use the material which has a very high ratio of absorptance to emittance, the temperature will be increased and when we use the material which has a very low ratio of absorptance to emittance, the temperature will be decreased. From this idea, we tried to find optimized surface property of the magnetometer by simulations in each different case, white paint, black paint and aluminum polished as shown in Figs. 14a-c.

\subsection{Results of Thermal Control Design}

Figs. 15 and 16 are results of thermal analysis after using passive thermal control design to CINEMA. Fig. 15 shows the temperature of the top solar panel using black paint to the surface of the inside of solar panel in the safe mode. The black square line indicates a new temperature of the top solar panel using black paint and the white circle line indicates original temperature of the top solar panel. By using black paint, we have increased the average temperature of the top \& bottom solar panels by $30^{\circ} \mathrm{C}$.

Table 11 shows the analysis results of the magnetome-
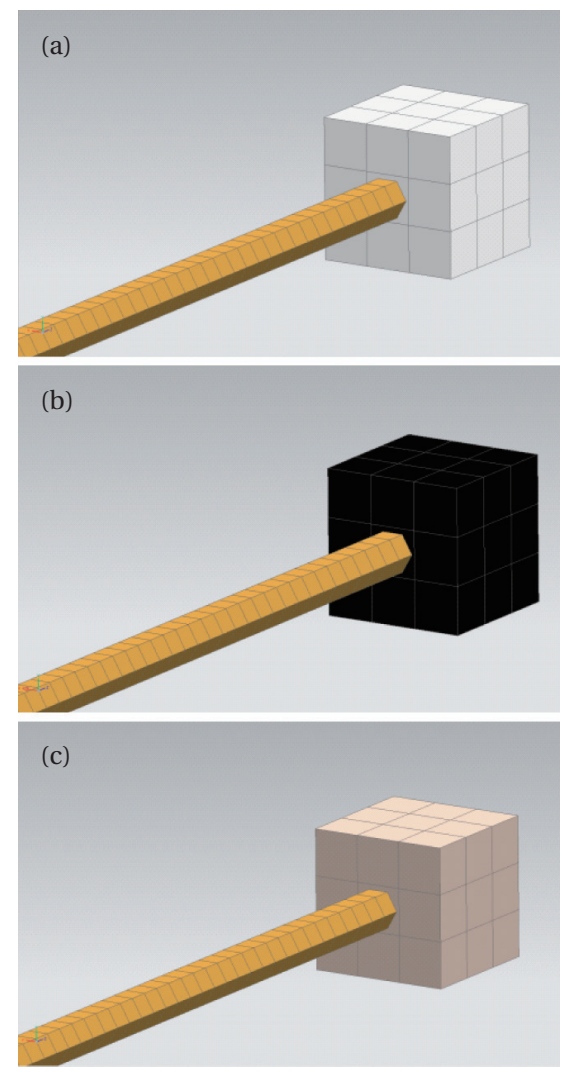

Fig. 14. (a) White paint as the surface of the magnetometer. (b) Black paint as the surface of the magnetometer. (c) Aluminum polished as the surface of the magnetometer. ter for different cases. From this result, we chose the black paint as the surface of the magnetometer because the average temperature of the magnetometer using black paint is the most optimal temperature for the magnetometer among others. Fig. 16 shows the temperature of the magnetometer using black paint to the surface in the safe and

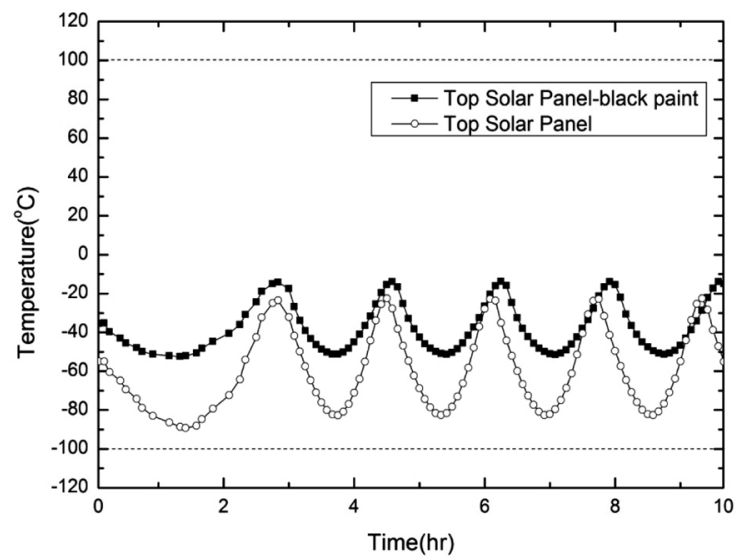

Fig. 15. Temperature of the top solar panel using black paint in the safe mode.

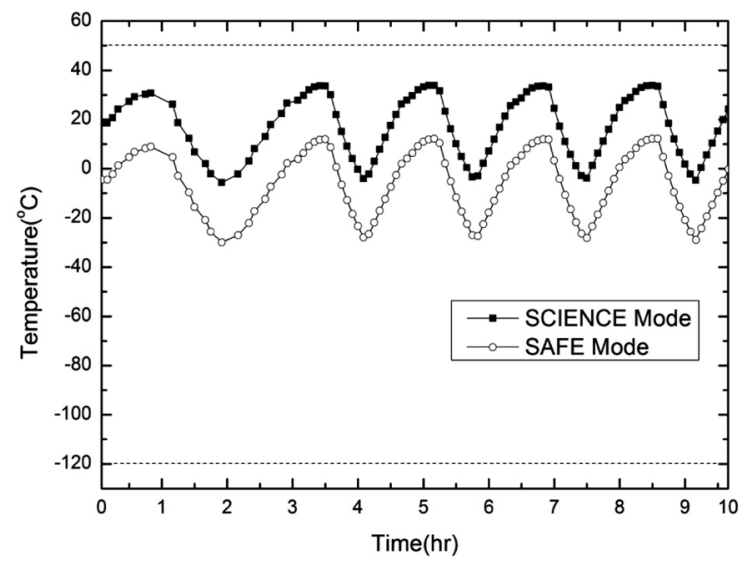

Fig. 16. Temperature of the magnetometer using black paint.

Table 11. Result of magnetometer.

\begin{tabular}{lc}
\hline \multicolumn{1}{c}{ Optical property } & Average temp $\left({ }^{\circ} \mathbf{C}\right)$ \\
\hline Alodined aluminum & 93 \\
White paint & -60 \\
Black paint & -4 \\
Aluminum polished & +62 \\
\hline
\end{tabular}

Table 12. Result of passive thermal control design in safe mode.

\begin{tabular}{cccccc}
\hline \multirow{2}{*}{ Components } & \multicolumn{2}{c}{ Before } & & \multicolumn{2}{c}{ After } \\
\cline { 2 - 3 } \cline { 5 - 6 } & $\begin{array}{c}\text { Average } \\
\text { temp }\left({ }^{\circ} \mathrm{C}\right)\end{array}$ & $\begin{array}{c}\text { Min, Max } \\
\text { temp }\left({ }^{\circ} \mathrm{C}\right)\end{array}$ & $\begin{array}{c}\text { Average } \\
\text { temp }\left({ }^{\circ} \mathrm{C}\right)\end{array}$ & $\begin{array}{c}\text { Min, Max } \\
\text { temp }\left({ }^{\circ} \mathrm{C}\right)\end{array}$ \\
\hline $\begin{array}{c}\text { Solar panel } \\
\text { (top \& bottom) }\end{array}$ & $-70 \sim-31$ & $-92 \sim-19$ & & $-40 \sim-21$ & $-60 \sim-10$ \\
Magnetometer & 93 & $87 \sim 98$ & & -4 & $-30 \sim 12$ \\
\hline
\end{tabular}


science mode. We can know that the temperature of the magnetometer using black paint is kept within their operating temperature limit. By using black paint, we have decreased the average temperature of the magnetometer by $-90^{\circ} \mathrm{C}$. Table 12 summarizes the analysis results of passive thermal control design.

\section{CONCLUSIONS}

As the CINEMA is a spin-stabilized satellite, it tends to be more stable for thermal environment in the space than 3 -axis stabilized satellite. In addition, satellite is less affected by thermal variation which is caused by sunlight, albedo and Earth IR because of their small surface and small size. From the thermal analysis result of this paper, we could know that the main components of CINMEA are within the operating temperature limits except the top \& bottom solar panel and the magnetometer. The black paint, which is the passive thermal control method, is able to increase $30^{\circ} \mathrm{C}$ of the average temperature of the top \& bottom solar panel. Besides, it is able to decrease $-90^{\circ} \mathrm{C}$ the average temperature of the magnetometer. At last, Solar panels and the magnetometer can maintain within their operating temperature limits by using black paint and all of the thermal requirements of CINEMA are met successfully by means of the passive thermal control design. The active thermal control design is not available in case of the nano-satellite because of power consumption and space limitation. Therefore the passive thermal control is better way to overcome thermal problems in the CubeSat scale satellite. We expect that this study is one of the important roles to develop the CubeSat mission.

\section{ACKNOWLEDGMENTS}

This research was supported by WCU program through the National Research Foundation of Korea funded by the Ministry of Education, Science and Technology (R3110016).

\section{REFERENCES}

Gilmore DG, Spacecraft thermal control handbook, volume 1: fundamental technologies, 2nd ed. (Aerospace Press, El Segundo, 2002).

Wertz JR, Larson WJ, Space mission analysis and design, 3rd ed. (Microcosm Press and Springer, New York, 2008), 428-458. 